LEITURA - ESPAÇOS HÍBRIDOS: n. 28, n.29, p.241-272.

\title{
FOUCAULT, FEMINISMO E QUESTÕES DA IDENTIDADE ${ }^{(+)}$
}

\section{Jana Sawicki ${ }^{(*)}$}

Resumo: A autora faz uma discussão filosófica acerca da importância do encontro das feministas com Foucault, a partir de questões da identidade, apontando de modo instigante os pontos onde tanto Foucault quanto as feministas podem ser criticados. Explora os escritos foucaultianos, que tratam dessas questões, e mostra as razões pelas quais o sujeito de Foucault pode servir para os debates feministas acerca da identidade. Para tanto, Sawicki traz ao cenário feministas como Susan Bordo e Sandra Bartky, que discutem a política de resistência foucaultiana em relação às tecnologias disciplinares, associadas ao complexo moda-beleza, cuja imposição da tirania da magreza traz imensos danos às mulheres. Sawicki também discute a relação do feminismo pós-humanista com Foucault. através de Nancy Hartsock, Judith Butler, Wendy Brown e Donna Haraway e, a partir do pensamento dessas feministas acerca das construções discursivas que circundam questões da identidade, constrói uma resposta própria para as práticas feministas em direção ao futuro da

(+) Publicado originalmente como "Foucault, feminism, and questions of identity". In: GUTTING, Gary (ed.). The Cambridge Companion to Foucault, Cambridge: Cambridge University Press, 1994, 6. ed., 1999, p. 286-313. Copyright (C)1994 by Cambridge University Press. Traduzido para o português com permissão da editora e da autora. A tradução é de Izabel Brandão, professora de literatura do PPGLL/UFAL. Meus agradecimentos especiais a Susana Funck, professora do Programa de Pós-Graduação em Lingüística Aplicada da Universidade Católica de Pelotas (UCPEL); a Walter Matias, professor do Departamento de Filosofia da Universidade Federal de Alagoas (UFAL); a Nádia Regina Loureiro de Barros Lima, professora aposentada de sociologia da UFAL e integrante do Grupo de Pesquisa Interdisciplinar Mare\&sal, do Núcleo Temático Mulher \& Cidadania (NTMC); a Lúcia de Fátima Santos, Lincoln Braga Villas Boas e Jerzuí Mendes Torres Tomaz, doutorandos em Lingüística e Literatura do Programa de Pós-Graduação em Letras c Linguiística da UFAL, pela leitura crítica da tradução e pelas contribuições para que o texto traduzido pudesse fazer jus à instigante leitura do original de Jana Sawicki.

(") Jana Sawicki é professora de filosofia e de estudos das mulheres do Department of Women's Studies do William College, Estados Unidos. 
política da identidade, algo que, para a autora, ocasionou-se devido ao encontro feminista com Foucault.

Palavras-chave: Foucault; questões de identidade; teoria e prática feminista; filosofia e crítica

Cada um dos meus trabalhos é parte da minha biografia.'

O maior interesse na vida é tornar-se alguém que você não era no começo ... O jogo é válido na medida em que não sabemos qual será o desfecho. ${ }^{2}$

Um movimento a favor da mudança habita nos sentimentos, ações e palavras. Tudo o que circunscreve ou mutila nossos sentimentos torna mais difícil agir, pois mantém nossas ações reativas, repetitivas: pensamento abstrato, lealdades tribais rígidas, todas as formas de pretensão, a arrogância de acreditar que estamos no centro. É difícil olhar para os limites da minha compreensão de um ou cinco anos atrás - como pude olhar sem ver, escutar sem ouvir? Pode ser difícil ser generoso com nossos eus passados, e manter a fé com a continuidade de nossas jornadas é ainda mais difícil nos Estados Unidos, onde as identidades e lealdades têm sido descartadas e substituídas sem um tremor, tudo em nome do tornar-se americano. Mesmo assim, se não for através de nós mesmos, efetivamente descobrimos o que leva as outras pessoas a mudarem? Nossos velhos medos e negações - o que nos ajuda a abandoná-los? O que nos faz decidir que temos de nos reeducar, inclusive aqueles de nós que têm uma "boa" educação? Uma vida politizada deve aguçar tanto o senso quanto a memória. ${ }^{3}$

Para muitos de seus leitores, as preocupações de Foucault com a subjetividade e as práticas do sujeito em seus escritos mais recentes são confusas e decepcionantes - até mesmo embaraçosas. Sua

Michel Foucault. "Truth, Power, Self: An Interview with Michel Foucault." in Tecnologies of the Self, eds. Luther Martin e Patrick Hutton. Amherst: The University of Massachussets Press, 1988, p.11.

2 Ibid, .9.

3 Adrienne Rich, "The Politics of Locations," in Blood, Bread, and Poetry. New York: Norton, 1986, p.223-24. 
mudança para uma estética do sujeito parecia na superfície desprezar sua proclamação inicial da morte do homem e de suas predileções anti-autoritárias pela autoria anônima. Além disso, parecia marcar um recolhimento do eu para longe dos textos mais engajados politicamente, tais como Vigiar e Punir, e a História da sexualidade, vol. I. Teria Foucault, o notável crítico "pós-humanista", retraído? Essa mesma questão manifesta uma preocupação, agora datada, por coerência e continuidade, em suma, pela identidade - na vida e obra de um autor. Contudo, se tomarmos Foucault literalmente, cada um de seus trabalhos pode ser entendido como "parte de sua [própria] biografia".

Nem é necessário muita imaginação para apreciar a verdade da afirmação de Foucault. É preciso pensar apenas nas suas preocupações com o papel do intelectual, a função da teoria, a produção histórica da identidade homoerótica, no contexto dos aparatos disciplinares da sexualidade moderna, o status das lutas para libertação sexual e as questões da autoridade epistêmica, literária e política. Seu esforço para tornar o papel de intelectuais, historiadores, teóricos sociais e ativistas o foco de uma análise geral, histórica e crítica, revela um grau memorável de autoconsciência. Todos esses eram papéis que ele ocupava com graus variados de desconforto.

Contudo, a hermenêutica foucaultiana do sujeito não era qualquer hermenêutica tradicional. Ele não mediu as profundezas do ser para descobrir uma verdade interior - uma experiência autêntica e decisiva -, nem escreveu simplesmente para se expressar, conforme observou um de seus comentaristas mais sensíveis, John Rajchman. Rajchman descreve a mudança de foco - a "crise" - do período recente de Foucault como uma busca por um novo estilo, por "outros métodos retóricos" que incluíssem suas questões iniciais acerca do conhecimento e do poder e "a questão do sujeito". "Ele associa a crítica foucaultiana da subjetividade (e a sua filosofia crítica de modo geral) à injunção socrática do conhecer-se. ${ }^{5}$ Escreve ele:

Há momentos em que as pessoas deixam de aceitar as práticas que as definem; momentos esses de 'dificuldade' na nossa constituição histórica de nós mesmos. Foi num

4 John Rajchman, Truth and Eros: Foucault, Lacan, and the Question of Ethics, p.4.

5 Ibid., p.7. 
desses momentos que Foucault pensou que as pessoas tivessem um tipo particular de experiência do pensamento crítico. Por essa razão, apresentou sua própria dificuldade consigo mesmo enquanto intelectual e historiador como parte de uma crise mais geral ou dificuldade na "função" do intelectual e do historiador, interligado à experiência de um fracasso nos ideais utópicos progressistas. Sua dificuldade seria, então, parte da nossa dificuldade enquanto pensadores críticos ou filósofos. ${ }^{6}$

O segredo é saber como praticar essa preocupação crítica por si mesmo. O eu autocognoscente de Foucault manifestou-se como um questionamento das formas dominantes de autocompreensão disponíveis no ocidente moderno, porque ele era cético quanto à eficácia do humanismo iluminista como filosofia da liberdade. Na sua pesquisa histórica ele identificara formas de dominação que operam através de mecanismos de assujeitamento, objetificação e normalização. Como resultado, ele preferiu a genealogia nietzschiana às narrativas hegelianas da evolução da liberdade - seja ela liberal ou marxista. Enquanto sua genealogia anterior enfocava os processos anônimos através dos quais os indivíduos constroem uns aos outros, suas genealogias do sujeito revelavam processos históricos através dos quais os indivíduos estabelecem relacionamentos com eles mesmos. Essa "subjetividade" é inteiramente histórica e de forma alguma monolítica ou privada; não é uma subjetividade cartesiana e sim nietzschiana ou heideggeriana. Ela se forma através de múltiplas "práticas do sujeito" - formas de nos conhecer e controlar, herdadas de tradições históricas. Foucault afirma: "o sujeito constitui-se através de práticas de assujeitamento, ou,... através de práticas de liberação, de liberdade... partindo naturalmente de um certo número de regras,
estilos e convenções que são encontradas na cultura.".

Foucault chama a nossa atenção para transformações históricas nas práticas de auto-formação para revelar sua contingência e nos liberar para novas possibilidades de auto-compreensão, novos modos de experiência, novas formas de subjetividade, autoridade e identidade política. Assim, o objetivo das auto-interrogações de Foucault não era auto-descoberta, e sim uma auto-recusa: - "de tornar-

\footnotetext{
${ }^{6}$ Ibid., 9.

${ }^{7}$ Michel Foucault, Foucault Live, ed. Sylvère Lotringer, p.313.
} 
se alguém que não se era no início". O que ele compartilha com o Iluminismo é o chamado à crítica que ele descobre no ensaio de Kant "O que é o Iluminismo?". O que ele rejeita é o seu apelo a universais e o seu embasamento num sujeito transcendental.

Busquei enfatizar aqui a centralidade das questões da identidade na vida e na obra de Foucault, porque elas representam um ponto de partida particularmente frutífero para descrever a recepção de sua obra pelas teóricas feministas. Questões de identidade tornaram-se ponto focal, de profunda tensão, dentro do feminismo, por mais de uma década. Afinal de contas, o feminismo é uma política da identidade de base gendrada e que tem um relacionamento ambivalente com o Iluminismo, o humanismo, com formas tradicionais de autoridade, inclusive com a própria feminilidade. Feministas aprenderam sobre os perigos do essencialismo e do universalismo na epistemologia e na política no contexto de suas próprias lutas políticas. Elas têm boas razões para suspeitarem de características universalistas, absolutistas, fundacionistas de epistemologias e teorias políticas iluministas. Apesar disso, elas também se utilizaram dessas teorias e epistemologias. Feministas brancas, de classe média, abraçaram, freqüentemente, sem intenção, categorias e conceitos universais de feminilidade que apagam as diferenças entre as mulheres (diferenças de raça, classe, orientação sexual, etnia, religião etc.), de formas paralelas ao seu próprio apagamento dentro do humanismo androcêntrico.

Mesmo assim, o feminismo é principalmente um movimento ocidental moderno com origens nas filosofias humanistas do liberalismo e do marxismo clássico. Apesar de haver boas razões para acreditar que a própria "feminilidade" seja uma construção masculinista, muitas feministas relutam em abandonar apelos a fundações absolutas - para algum sujeito essencial, liberador, enraizado na "experiência das mulheres" (ou da natureza) - como um ponto de partida para uma teoria emancipatória. Assim, embora questões de identidade e das tecnologias de poder/conhecimento que as produzem tenham estimulado muitas das apropriações feministas da análise foucaultiana por volta dos anos 80, elas também marcam pontos de tensão no relacionamento entre Foucault e o feminismo (e

8 Ver Susan Hekman, Gender and Knowledge: Elements of a Postmodem Feminism. Boston: Northeastern University Press, 1990, p.186ff. 
no interior do próprio feminismo). Conforme observa a teórica feminista Linda Zirelli em outro contexto: "Talvez a política radical de qualquer história feminista, por assim dizer, está menos no próprio texto do que nos debates por ele ocasionados; menos no movimento de qualquer narrativa específica do que nas interpretações contestadas, geradas por comunidades de leitores/as feministas.",

Debates entre feministas acerca das implicações das teorias e políticas de Foucault enfatizam tensões concernentes a questões de identidade, tais como as seguintes: De que maneira são viáveis as políticas de base identitária? Há identidades disponíveis como base para a organização política, para a construção de um movimento unificado? Devemos descartar apelos à categoria de gênero a fim de evitar o essencialismo? Qual o papel de narrativas experimentais de grupos oprimidos numa política pós-humanista? Precisamos de uma noção transcendental ou quase-transcendental de subjetividade para "fundar" agenciamento e crítica política? Pode-se definir uma política operacional sem qualquer forma de epistemologia feminista fundacional, ou outra? Sem a base em teorias de estruturas sociais, econômicas e políticas nacionais ou internacionais e seus interrelacionamentos? Precisamos de uma teoria da resistência? Qual o papel das teóricas feministas nas lutas das mulheres? No que se segue, pretendo mapear parte do território dos feminismos foucaultianos num esforço de discutir essas questões.

\section{Feminismo e Foucault: convergências e críticas}

A obra de Foucault tem sido de interesse especial para teóricas feministas sociais e políticas. Entre os muitos discursos pós-modernos influentes, os de Foucault se destacam na medida em que são apresentados de forma desconfortável como intervenções ${ }^{10}$ em lutas

9 Linda Zirelli, "Rememoration or War? French Feminist Narrative and the Politics of Self-Representation," in Differences: A Journal of Feminist Cultural Studies (Spring 1991): 17.

10 A filosofia crítica de Foucault tem sido sedutora, mas também problemática para as feministas. Em uma das mais equilibradas avaliações das implicações dos seus escritos intermediários (Vigiar e punir e A história da sexualidade) para a teoria política emancipatória na literatura crítica, Nancy Fraser provocativamente afirma que enquanto ela não recomendaria casar-se com ele, Foucault "torna-se de fato um amante muito interessante" (Unruly Practices:Power, Discourse and Gender in Contemporary Social Theory, p.65). Por que "amante" c não "marido". 
específicas de grupos oprimidos, tais como de pessoas homoeróticas, prisioneiros e doentes mentais. Suas análises das formas disciplinares de poder exercidas fora dos limites rigidamente definidos do domínio político do estado liberal moderno superpõem-se aos insights feministas sobre políticas da vida pessoal. Sua ênfase no corpo sexual como um alvo e veículo dessa nova forma de poder/conhecimento é reproduzida nas análises feministas das formas modernas de controle patriarcal sobre as mentes e corpos das mulheres no contexto da emergência da assistência social, da psicologia e das ciências da medicina. Além disso, como já indiquei, sua crítica ao humanismo iluminista e seus apelos a um sujeito autônomo do conhecimento e da história espelham até certo ponto os desafios radicais postos pelo feminismo às postulações fundamentais epistemológicas e políticas do pensamento moderno ocidental. O ceticismo foucaultiano em relação ao essencialismo e universalismo nas teorias modernas emancipatórias

Podemos tolerar qualidades num amante que são inaceitáveis num marido. Como amante, "o próprio atrevimento [de Foucault] ao rejeitar virtudes humanistas padrões, convenções narrativas e categorias políticas apenas nos dá a sacudida necessária ocasionalmente para des-reificar nossos padrões habituais de auto-interpretação e renovar nosso senso de que, apenas possivelmente, eles podem não dar conta de toda a história" (65). O ponto de Fraser é que embora o encontro das feministas com Foucault produza excitação e ocasione auto-reflexão por parte das teóricas feministas, ele é em última análise muito egoísta, inconsistente, e não confiável para tornar um compromisso recomendável. Devemos amálo, aprender o que pudermos e abandoná-lo.

As metáforas de casamento e de caso parecem-me caracterizações inapropriadas do relacionamento de Foucault com as feministas, principalmente porque obscurecem seu homoerotismo. Muitas feministas consideram a obra de Foucault fascinante exatamente porque, como elas, cle também desafiou a heterossexualidade compulsória e os paradigmas hegemônicos de masculinidade. Nem amante, marido, nem figura paternal, Foucault é muito mais um irmão mais velho ou um amigo com quem temos lutas em comum. Mesmo assim, como muitos homens gays, ele se identifica predominantemente com os homens. Como veremos, esse androcentrismo limita as possibilidades de uma colaboração bem sucedida pois cria tensões no relacionamento.

Claro que os relacionamentos centrais, que estão em jogo na apropriação feminista de Foucault, são aqueles que se desenvolvem entre as feministas como resultado desse encontro. 
coincide com o ceticismo feminista sobre o uso do marxismo e do liberalismo para a política emancipatória feminista.

As apropriações feministas de Foucault têm se valido principalmente das genealogias do poder/conhecimento encontradas em seus escritos (livros e entrevistas) a partir dos anos setenta. Podemos classificá-las, grosso modo, em dois campos: aquelas que usam suas análises de poder disciplinar para isolar as tecnologias disciplinares que subjugam as mulheres tanto como sujeitos quanto objetos do conhecimento; e aquelas que reconhecem a dominação mas privilegiam culturas e estratégias de resistência aos sistemas hegemônicos de poder/conhecimento.

\section{O "assujeitamento" das mulheres}

Exemplos desse "assujeitamento" estão no estudo de Sandra Bartky sobre o "complexo de moda/beleza" na América contemporânea e na análise cultural de Susan Bordo sobre anorexia nervosa. ${ }^{11}$ Bartky faz poderosas descrições de tecnologias disciplinares que produzem especificamente formas femininas de incorporação, tais como regimes dietéticos e de boa forma, discursos especializados sobre como andar, falar, estilo de cabelo, cuidado com a pele e uso de maquiagem. Essas tecnologias subjugam as mulheres através do desenvolvimento de normas e competências e não meramente da diminuição de seu poder. As mulheres ligam-se a essas tecnologias em parte porque elas envolvem a aquisição de habilidades, porém principalmente porque estão ligadas a um componente de identidade feminina normativa, ou seja, o sex-appeal. Para Bartky, muitas mulheres ignoram críticas feministas ou resistem a elas e aos padrões aceitos de moda e beleza porque abandoná-los significa desafiar o próprio senso de identidade. Assim, o poder patriarcal afirma-se ao associar as mulheres a certos paradigmas de identidade feminina.

Susan Bordo usa insights foucaultianos para mostrar como o "complexo de beleza/moda" com a sua "tirania da magreza" produz

1 Sandra Lee Bartky, "Foucault, Femininity and the Modernization of Patriarcal Power," in Femininity and Domination: Studies in the Phenomenology of Oppression (New York: Routledge Press, 1990), p.6382 e Susan Bordo, "Anorexia Nervosa: Psychopathology as the Crystallization of Culture", in Diamond and Quinby (eds), Feminism and Foucault: Reflections on Resistance, p.87-117. 
formas patológicas de subjetividade que podem também ser entendidas como uma cristalização da produção cultural de feminilidade "normal". Bordo faz uma fascinante análise das desordens alimentares epidêmicas atuais como tecnologias disciplinares do corpo. Seguindo Foucault, ela trata o corpo como um produto de práticas culturais que modelam e manipulam não apenas o corpo físico mas também o modo pelo qual as mulheres vivenciam as experiências de seus corpos. Ela argumenta que a manipulação social dos corpos femininos têm sido uma estratégia-chave para a manutenção das relações de poder entre os sexos por mais de um século. A anorexia nervosa representa a imposição patológica, por isso extrema, de regimes dietéticos e de boa forma amplamente estimulados e que têm sido associados a novas normas do indivíduo saudável, atraente e disciplinado, na América contemporânea. Os regimes dietético e de boa forma da anoréxica estimulam seu senso de vontade de poder e autocontrole ao mesmo tempo em que destroem seu corpo físico. A alma, literalmente, torna-se a prisão e a torturadora do corpo.

Muitas anoréxicas representam esse "torturador" como masculino. Bordo cita Hilde Bruch, que diz:

muitas anoréxicas falam sobre ter um "fantasma" dentro ou em torno delas, um "ditador que me domina," conforme descreveu uma mulher; "um homenzinho que reclama quando eu como" é a descrição dada por outra .... Este fantasminha, o ditador, (o "outro self" conforme ele é frequientemente descrito) é sempre masculino.... O outro self da anoréxica - o self dos apetites incontroláveis, das impurezas e manchas, da vontade frouxa e tendência ao torpor mental - é o corpo .... Mas é também (e aqui as associações da anoréxica estão certamente na corrente principal da cultura ocidental) o self feminino. Perceptivelmente esses dois eus estão em constante guerra. Contudo, fica claro que é o lado masculino - com seus valores associados de grande espiritualidade, alta intelectualidade, força de vontade - que está sendo expressado e desenvolvido na síndrome anoréxica. ${ }^{12}$

12 Bordo, "Anorexia Nervosa", p.101. 
Bordo analisa o significado dessas associações de gênero em dois níveis: - o do desdém que a anoréxica sente pelos papéis tradicionais femininos e as restrições sociais a eles associadas, e o do medo "do Feminino" que ela tem, por causa das imagens de "fomes vorazes e insaciabilidade sexual" por ele invocadas, ou seja, imagens de mulheres (e do feminismo?) como "excessivo."13 Seguramente, nos sintomas anoréxicos há um grau de protesto feminino contra as restrições sociais impostas às mulheres. Entretanto, isso não é uma protesto político consciente, conforme nos lembra Bordo, e sim, um protesto "escrito no corpo das mulheres anoréxicas". ${ }^{14}$ Não reflete qualquer compreensão social ou política. De fato, a anorexia é tão impressionante que impede a possibilidade de se ganhar tal compreensão e participação num protesto político. Assim, tanto o protesto patológico e mesmo exemplos mais moderados da busca de magreza são contraproducentes porque tomam tempo e energia do crescimento pessoal e social e do ganho político. O impulso à resistência é recanalizado e, portanto, neutralizado.

Finalmente, Bordo não afirma que essas práticas culturais foram impostas conscientemente pelos homens. Elas não representam as maquinações de uma conspiração masculina. Novamente, seguindo Foucault, ela as descreve como intencionais mas não-subjetivas. Há uma lógica patriarcal para as relações históricas de poder exibidas nelas, mas essa lógica não é uma invenção de qualquer indivíduo ou grupo.

O uso que Bartky e Bordo fazem de Foucault corrige uma falha que todas as feministas encontram nos seus escritos. Elas percebem o caráter específico de gênero de algumas das tecnologias disciplinares desenvolvidas num nível micropolítico no período moderno. Mesmo assim, ambas reproduzem uma dimensão da explicação foucaultiana das práticas disciplinares modernas que é, para muitas, problemática. Apesar de rejeitar a teoria totalizante e o fechamento das narrativas teleológicas, a retórica holística de Foucault e suas, por vezes estridentes, condenações da sociedade carcerária em Vigiar e punir emprestam suporte àqueles que afirmam que, neste livro, ele descreve uma sociedade totalmente disciplinada. Foucault parece, às vezes, realmente invocar um poder disciplinar infinitamente capaz de alistar forças de resistência a serviço da dominação. Em suma, ele não fornece

\footnotetext{
13 Ibid., p. 102.

14 Ibid., p. 105.
} 
explicação convincente sobre a eficácia possível da resistência ao poder. Similarmente, pode-se argumentar, Bartky e Bordo mostram formas de poder patriarcal que se insinuam dentro dos sujeitos de forma tão profunda que é difícil imaginar como eles (nós) podem escapar. Elas descrevem nossa cumplicidade nas práticas patriarcais de vitimização sem fornecer sugestões de como podemos resistir-lhes. Nem há tampouco uma explicação sustentável de resistência nas suas histórias.

Em outro trabalho já argumentei que, apesar da retórica holística em Vigiar e punir, os comentários de Foucault sobre esse livro indicam que ele não foi pensado como um retrato do todo da sociedade, e sim como uma genealogia da emergência do ideal de uma sociedade perfeitamente administrada. O Panóptico de Betham funciona não como uma metáfora para a sociedade moderna, mas como um modelo teórico que deve ser analisado em termos de seu impacto. ${ }^{15}$ Além disso, a narrativa distópica do declínio poderia ser entendida enquanto anti retórica para as histórias de progresso whiggishiano. $O$ poder, na análise foucaultiana, não é nem determinista nem sistêmico de uma maneira fechada.

A resposta de Bartky para a acusação de "pessimismo" em seu próprio trabalho também poderia ser alistada para dar suporte a Foucault, que, afinal de contas, referiu-se a si próprio como um "pessimista hiperativo". Escreve ela:

A maioria dos meus artigos ... enfocam não aquilo que é positivo na experiência das mulheres, mas aquilo que não é, ou seja, na ansiedade, medo e obsessões caracteristicamente femininas: em uma palavra, na internalização das insinuações prevalentes de inferioridade. As alegrias e triunfos femininos não são meus temas. Compreendo que isso pode dar um tom um tanto quanto pessimista à coletânea. Contudo, isso não é tudo. Trabalho teórico feito a serviço de fins políticos podem exibir um "pessimismo do intelecto", mas o sentido de fazer algo assim é aquele "otimismo da vontade" sem o qual qualquer trabalho político sério é impossível. ${ }^{16}$

15 Jana Sawicki, "Feminism and the Power of Foucaultian Discourse: Foucault and Mothering Theory", in Disciplining Foucault: Feminism. Power and the Body. New York: Routledge Press, 1991, p.58.

16 Bartky, "Introduction" in Femininity and Domination, p.7. 
Tanto Bartky quanto Foucault querem afirmar que há um valor na crítica negativa, crítica esta que não fornece uma política ou estratégia para resolver as dificuldades numa situação. A descrição adequada feita por John Rajchman da tarefa do pensamento crítico de Foucault fornece outra defesa dessa visão:

Uma tarefa para o "pensamento crítico" é, pois, expor [os custos de nossa auto-constituição], a fim de analisar o que não pensamos ser necessário fazer por nós mesmos para ser quem somos ... A experiência do pensamento crítico começaria na experiência desses custos. Assim, antes de perguntar, ou pelo menos ao perguntar, o que devemos fazer para nos comportarmos racionalmente. esse tipo de pensamento deveria perguntar: Quais são "as formas de racionalidade" que asseguram a nossa identidade e delimitam nossas possibilidades? Ou deveria perguntar o que é "intolerável" acerca dessas formas de razão? ${ }^{17}$

O importante aqui é o simples fato de que a opressão deve ser experienciada antes que possa ser efetivamente resistida. Logo, um papel necessário para o intelectual é exercitar o pensamento crítico em áreas específicas da experiência moderna no sentido de criar uma experiência de suas intolerâncias. Através da análise, descrição e crítica das relações de poder/conhecimento, Foucault esperava criar o de "psco necessário para a resistência, para aproveitar o que ele chamou de "polivalência tática" de discursos e práticas e para desenvolver estratégias oposicionais e novas formas de experiência.

Bartky alude à possibilidade de que mesmo as tecnologias disciplinares do "complexo de moda/beleza" podem produzir possibilidades de resistência. Imagens de mulheres fortes e alternativos de gênero. A experiência espaço para arranjos intensa auto-estima e ao empoderamento boa forma pode levar a contribua para objetivos feministas.

17 Rajchman, Truth and Eros, p.11. 
Foucault também afirma que o poder nunca é conquistado em definitivo; existem sempre possibilidades de resistência. ${ }^{18}$ Apesar disso, os temas de resistência e agenciamento político permanecem não desenvolvidos e um tanto quanto vagos nos escritos de Foucault. Ele escapa por entre descrições de poder (dominação?), que parecem enfatizar sua capacidade de co-optar todas as formas de resistência e de reprodução de discursos hegemônicos, e discursos que enfatizam forças micropolíticas de resistência. Há também a famosa e confusa invocação de "corpos e prazeres" no final de História da sexualidade, vol. I, que muitos/as comentaristas entenderam como um apelo não intencional para um corpo pré-discursivo. ${ }^{19}$ Finalmente, há comentários que sugerem que a identidade política envolve participação em práticas dominadoras de "assujeitamento". Claro que uma crítica negativa sempre pressupõe alguma noção de agenciamento crítico e auto-reflexão crítica. ${ }^{20}$ Embora Foucault tenha recusado qualquer papel legislativo ou profético para si próprio, o objetivo de seus escritos era oferecer interpretações de práticas e idéias específicas que pudessem ser usadas, politicamente, para oferecer descrições que sugerissem "trilhas possíveis de ataque". Ele descreveu seu objetivo assim: "Gostaria de produzir alguns efeitos de verdade que pudessem ser usados para uma possível batalha, a ser lutada por aqueles que desejam lutá-la, em formas ainda a ser encontradas e em organizações ainda por ser definidas." 21 Foucault parece estar desafiando pessoas comprometidas com movimentos emancipatórios a desenvolver formas e compreensões da luta política.

Para examinar os temas da identidade, subjetividade, resistência e agenciamento desenvolvidos de forma a construir e desenvolver a posição de Foucault, devemos nos voltar para outro grupo de textos feministas. Contrastando com o uso que Bartky e

18 Conforme argumento em meu livro, em resposta às críticas a Vigiar e punir, Foucault em última análise fez uma distinção entre relações de dominação e relações de poder. As primeiras não deixam espaço para uma luta eficaz, ao passo que as outras são contestáveis e alteráveis.

19 Ver Judith Butler, "Foucault and the Paradox of Bodily Inscriptions," in Journal of Philosophy 86, no.11, p.601-7.

20 Se a noção de resistência de Foucault é incoerente, porque pressupõe uma explicação de subjetividade que ele já havia refutado, é uma questão que será discutida adiante.

21 Foucault Live, ed. Sylvère Lotringer, p. 191. 
Bordo fazem de Foucault para descrever formas particulares de dominação masculina e de "assujeitamento" feminino, encontram-se feministas que tentam desenvolver os esboços de uma política póshumanista implícita em seus escritos.

\section{Pós-humanismo e política: o SUJEITO do feminismo}

Um dos debates-chave dentro do feminismo, originado a partir do encontro com Foucault, diz respeito à validade do desenvolvimento de epistemologias feministas, em particular, epistemologias focais fundadas no trabalho e nas práticas historicamente constituídas de mulheres no contexto de uma divisão de trabalho que tenha gênero em sua base. Um breve exame de pontos-chave nesse debate servirá não apenas para esclarecer a base das críticas feministas de Foucault, mas também para enfatizar aqueles discursos feministas que, foucaultianos em espírito, respondem ao seu desafio de pensar além das tradições e categorias emancipatórias. Judith Butler, Wendy Brown, e Donna Haraway desenvolveram esboços de um feminismo pós-humanista baseado em críticas das teorias emancipatórias. O que é notável sobre esses esforços é a vontade dessas feministas de responder ao desafio de começar a pensar além das categorias e práticas da teoria modernista social e política. Cada uma das suas posições pode ser lida em parte como uma resposta - indireta ou direta - para a relutância feminista em desistir de suas reivindicações em favor das origens inocentes e de uma identidade unificada como base para as lutas morais epistemológicas e políticas. Muito do que criticam no feminismo contemporâneo é encontrado nos esforços das teóricas do feminismo focal ${ }^{22}$, como Nancy Hartsock. Na sessão seguinte vou expor a crítica de Hartsock a Foucault e depois usarei essas feministas pós-humanistas para desenvolver uma resposta. Minha preocupação aqui é menos com o desenvolvimento de uma resposta crítica ao feminismo pós-humanista e mais com a sua

22 N.T.: Feminismo focal [standpoint feminism] parte da idéia de que as mulheres vêem o mundo diferentemente dos homens e suas experiências podem servir de base a uma visão liberadora. Uma das defensoras desse tipo de feminismo é Nancy Hartsock, que pensa ser possível, a partir daí, provocar uma mudança no mundo. Assim, o feminismo focal pode ser definido como uma posição necessariamente engajada do ponto de vista político. Cf. para maior informação sobre o assunto, o artigo "The Feminist Standpoint, de Nancy Hartsock, in Nicholson, L (ed.). The Second Wave - a Reader in Feminist Theory. New York: Routledge: 1997, p.216-241. 
apresentação como direção viável, ainda que problemática, para uma futura prática feminista. Posteriormente, farei uma avaliação crítica dos debates concernentes ao futuro da política da identidade, ocasionada pelo encontro feminista com Foucault.

Meu objetivo não é tanto defender Foucault, pois muita coisa permanece implícita e vaga em suas próprias afirmações sobre identidade e política, mas defender a importância de se levar a sério as questões por ele levantadas. Muitas respostas feministas a Foucault pecam por não compreenderem as questões radicais que ele apresenta, preferindo descartar muito do que ele disse porque ele não fornece uma alternativa sistemática para as teorias marxistas ou liberais tradicionais. Outras engajaram-se seriamente nas questões postas por ele ao imaginarem os esboços de uma política que poderia fluir dos seus escritos. Se essa política é operacional ou necessária permanece uma questão em aberto. Contudo, respostas a Foucault que mantêm abertas as questões que ele levanta são certamente mais úteis do que aquelas que simplesmente as negam.

Nancy Hartsock, uma importante teórica feminista focal e crítica do pós-estruturalismo, argumenta que a suposta rejeição "total" que Foucault faz da modernidade e das suas teorias emancipatórias, a sua recusa de prever ordens alternativas e sua ênfase na resistência e na desestabilização, ao invés de transformação, roubam do feminismo elementos que são indispensáveis para seus objetivos emancipatórios. Hartsock observa que "sistematicamente as relações desiguais de poder finalmente desaparecem da obra de [Foucault]". ${ }^{23}$ Para ela, a análise instável de poder feita por Foucault leva à vitimização, na medida em que enfatiza a participação de agentes ${ }^{24}$ na sua própria

23 Nancy Hartsock, "Foucault on Power: A Theory for Women?" in Feminism/Postmodernism, ed. Linda Nicholson, p.168.

24 Hartsock pergunta: "Por que é que justo quando tantas de nós passamos a agir como sujeitos e não objetos da história, o conceito de sujeito torna-se problemático? Justo quando estamos formando nossas teorias sobre o mundo, incerteza emerge sobre se o mundo pode ser teorizado. Justo quando estamos falando sobre as mudanças que queremos, idéias de progresso e a possibilidade de sistemática e racionalmente organizar a sociedade humana torna-se suspeita e questionável. Por que é que somente agora essas críticas são feitas da vontade de poder inerentes ao esforço de criar teoria?" Ver "Foucault on Power". Ver também Barbara Christian. "The Race for Theory", Cultural Critique 6 (Spring 1987), p.51-63. 
opressão. Assim como a crítica literária feminista Barbara Christian, Hartsock tem dúvidas sobre os movimentos de Foucault rumo à rejeição do sujeito e das teorias universais de história, num momento em que grupos marginais estão finalmente rompendo o silêncio, rejeitando seu status de objeto no interior de discursos dominantes e construindo políticas oposicionais de subjetividades, teorias e visões progressistas próprias. Por fim, ela afirma que a analítica do poder foucaultiano frustra o feminismo porque não é uma teoria desenvolvida para as mulheres. É a teoria de um colonizador que resiste aos colonizadores e os rejeita, mas que, por não pensar a partir da perspectiva do colonizado, "deixa de proporcionar uma epistemologia que seja útil para a tarefa de revolucionar, criar e construir." 25 Ela vê como distópica e inaceitável a perspectiva hobbesiana de Foucault da luta como uma "guerra de todos contra todos". Numa leitura mais amena das contribuições de Foucault para a teoria crítica, Joan Cocks faz eco a Hartsock, quando comenta acerca das limitações das tendências anárquicas de Foucault:

Devemos ter claras as duas grandes fraquezas de [Foucault], ambas inerentes ao anarquismo: a inabilidade de sustentar qualquer movimento que através de sua unidade massiva e disciplinada, fosse ao mesmo tempo popular e suficientemente poderosa para minimizar um regime político-legal entrincheirado; e a completa inabilidade de permanecer ao lado de qualquer nova ordem político-cultural positiva que fosse sempre, e ao mesmo tempo, um novo sistema de proibições e permissões, cuja oposição propriamente dita apenas pode responder negativamente. Tais inabilidades são sintomas de pouca firmeza ante a questão da ordem - que, afinal de contas, cada modo tolerável e intolerável de vida social pode ter e terá, e que qualquer contramovimento em alguma encruzilhada terá que ser desenvolvida também. ${ }^{26}$

25 Hartsock, "Foucault on Power", p.164.

26 Joan Cocks, The Opposiotional Imagination: Feminism, Critique and Political Theory (New York: Routledge, 1989), p.74. Ver também Ann Ferguson, Blood at the Root: Motherhood, Sexuality, and Male Domination (London: Pandora Press, 1989), para uma crítica semelhante. 
Assim, as críticas mais mordazes feitas pelas feministas a Foucault identificam dois grandes defeitos em sua obra: sua rejeição das epistemologias fundacionais (e suas filosofias do sujeito) e a questão correlata da adequação de sua política de resistência. (Quem resiste ao poder? Qual é a sua fonte? A quais fins deve a resistência almejar?). Essas críticas feministas a Foucault sobrepõem-se de forma significativa a críticas de teóricos sociais e políticos não feministas. ${ }^{27}$ Assim, apontam para o perigo do relativismo, pessimismo e niilismo sempre associado à sua obra.

O que propõe Hartsock em lugar disso? É importante observar que Hartsock liga a inadequação da explicação foucaultiana de poder e conhecimento à sua localização social como homem branco privilegiado, pois a lógica de sua epistemologia focal compromete-a à visão de que certas situações são mais passíveis de produzir distorções e visões parciais do que outras. Empregando uma revisão feminista da epistemologia focal marxiana, ela argumenta a favor do privilégio epistêmico do feminismo focal. Entre as características que ela identifica como essenciais a esta teoria revisada estão as seguintes:

Primeiro, ao invés de livrar-se da subjetividade ou de noções do sujeito, como faz Foucault, e substituindo sua noção de indivíduo como efeito das relações de poder. precisamos nos engajar no processo histórico, político e teórico de nos constituirmos como sujeitos e objetos da história... Segundo .... se formos construir uma nova sociedade, precisamos ter certeza de que algum conhecimento sistemático sobre nosso mundo e sobre nós mesmos é possível.... Terceiro ..., precisamos de uma teoria de poder que reconheça que nossas atividades práticas cotidianas contêm uma compreensão do mundo ... uma epistemologia "focal" [baseada] na reivindicação de que a vida material ... não apenas estrutura, mas estabelece limites à compreensão das relações sociais e que, em sistemas de dominação, a visão disponível dos governantes será tanto parcial quanto reverterá a ordem real das coisas [minha ênfase]. ${ }^{28}$

27 Para exemplos dessa crítica não feminista, ver artigos de Taylor, Walzer. e Habermas in Foucault: A Critical Reader, ed. Hoy.

28 Hartsock, "Foucault on Power", p.171-72. 
Segundo Hartsock, a teoria de poder de Foucault é problemática na medida em que ele supostamente rejeita a subjetividade (e a possibilidade de agenciamento transformador), conhecimento sistemático e fundacionismo epistemológico.

Que respostas à crítica de Hartsock estão disponíveis a uma feminista foucaultiana? Será que a ênfase de Foucault nos processos produtivos através dos quais indivíduos e subjetividades são produzidas implica de fato uma total rejeição da subjetividade?

Num esforço brilhante e imaginativo, ainda que problemático, de pensar além das concepções modernas da política e identidade, Judith Butler oferece uma resposta significativa para essa questão. Butler argumenta que política feminista sem um sujeito feminista é "possível e desejável. Mas a estrutura usada por ela, a noção de um "sujeito feminista" refere-se a uma identidade estável e fixa (natural ou social) que serve como base e ponto de referência das teorias e políticas feministas. O que ela objeta sobre política de base identitária é a tendência de "assumir que uma identidade deve em primeiro lugar estar no seu lugar para que interesses políticos sejam elaborados e, subsequientemente, uma ação política seja tomada.,"29 De modo nietzschiano, ela argumenta que o feminismo não precisa assumir que há um "ator por trás do ato", e sim que "o 'ator" é construído de forma variável dentro e através do ato." ${ }^{30}$

Críticas - feministas e outros/outras - das críticas pósestruturalistas ao sujeito estão erradas ao concluir que a visão de que o sujeito é discursivamente construído exclui a possibilidade de agenciamento. A linguística socio-construcionista não implica determinismo histórico. Pelo contrário, afirma Butler: "Construção não se opõe a agenciamento; é a cena necessária do agenciamento.". As feministas confundem construcionismo social com determinismo porque se deixaram apanhar na lógica binária do pensamento ocidental no qual a idéia do livre-arbítrio pressupõe uma forma de agenciamento que escapa ao mundo onde deve negociar sua identidade - um eu que está no máximo "incorporado" e "atolado" no discurso, como no existencialismo sartriano, mas nunca completamente constituído por

\footnotetext{
29 Judith Butler, Gender trouble: Feminism and the Subversion of Identity (New York: Routledge Press, 1990), p. 142.

30) Ibid.

3 Ibid., p. 147.
} 
ele. 32 (Mais uma vez, "constituição" não é uma noção determinista.) Ao elaborar essa visão do sujeito foucaultiano, Butler descreve identidades como auto-representações, "ficções" que não são nem fixas nem estáveis. O sujeito não é uma coisa, uma entidade substantiva e sim um processo de significação dentro de um sistema aberto de possibilidades discursivas. O sujeito é um conjunto de práticas reguladas, mas não determinadas. Uma dessas práticas envolve a reificação do próprio sujeito. Confundimos o sujeito com uma coisa devido à nossa participação nas tradições discursivas cartesianas e finalmente hegelianas, que postulam uma dicotomia do sujeito/objeto e identificam liberação com o projeto epistemológico da descoberta do sujeito da sua presença no mundo objetivo.

Embora Hartsock não seja nem cartesiana nem a-histórica, sua visão do sujeito do feminismo parte da tradição hegeliana e marxista ao apelar para uma base essencial de crítica, isto é, o foco do oprimido. O momento essencializante na sua epistemologia focal é o esforço que faz para basear sua crítica no "trabalho das mulheres" um espaço de práticas que, conforme afirma, contém a base para um conhecimento transformador e emancipatório da sociedade.

Por que devemos desafiar essa tradição? Seguindo Heidegger, Butler associa esse sujeito/objeto pensante a uma racionalidade instrumental que leva à dominação do Outro. Segundo afirma: "A linguagem da apropriação, instrumentalidade e distanciamento verdadeiramente relevante ao modo epistemológico também pertence a uma estratégia de dominação que põe o "eu" contra um "Outro" e, uma vez efetuada a separação, cria-se um conjunto artificial de questões sobre a possibilidade de conhecimento e recuperação daquele Outro" ".3 A lógica binária do sujeito/objeto é em si mesma uma lógica historicamente contingente embutida dentro de uma tradição discursiva que esconde sua função produtiva ao reificar e naturalizar os seus efeitos. Essa tradição discursiva é parte tão integrante de nós

32 Essa explicação de uma subjetividade não cartesiana que está sempre num mundo e para a qual as distinções de interno/externo, e ativo/passivo não se aplicam em nenhum sentido familiar é também encontrado $\mathrm{cm}$ Heidegger. No último capítulo de Disciplining Foucault, sugeri que o sujeito ao qual Foucault apela é um sujeito crítico, criativo, "nadificante" [nihilating], semelhante ao sujeito descentrado sartriano. Contudo. hoje penso que o sujeito foucaltiano é mais nietzschiano do que sartriano.

33 Butler, Gender trouble, p.147. 
que se torna difícil pensar em quaisquer outros termos, ou reconhecêla quando alguém o faz.

Butler parece recomendar que feministas considerem a explicação epistemológica da identidade como simplesmente uma prática discursiva que não deve servir como árbitro de todas as possibilidades. Além disso, seu argumento central é que quaisquer políticas feministas que atuem ao instalar identidades de gênero alternativas como base para a política da identidade estão sujeitas a reproduzir práticas normativas e, portanto, exclusionárias, associadas às configurações masculinistas de gênero que buscam superar.

Há uma ontologia de gênero sobre a qual deveríamos construir uma política, pois ontologias de gênero sempre operam dentro de contextos políticos estabelecidos como injunções normativas, determinando o que qualifica como sexo inteligível, invocando e consolidando as restrições reprodutivas na sexualidade, estabelecendo as exigências prescritivas pelas quais corpos sexuados ou gendrados surgem na inteligibilidade cultural. A ontologia não é, portanto, fundante e sim, uma injunção normativa que opera insidiosamente ao instalar-se no discurso político como o seu fundamento necessário. ${ }^{34}$

Muito do livro de Butler consiste de análises críticas de explicações influentes da produção de gênero, que, apesar de suas intenções radicais, continuam a reproduzir ontologias não examinadas de gênero, normativas e heterossexistas.

É claro que afirmar que o sujeito e suas identificações são meros efeitos de práticas de significação não é o mesmo que afirmar que esses efeitos não são reais, ou que a identidade é artificial e arbitrária. Práticas discursivas que constroem gênero são estruturas hegemônicas de inteligibilidade que restringem tanto quanto possibilitam a formação da identidade. Vendo a identidade como nem totalmente determinada nem totalmente arbitrária, a visão promulgada aqui tenta mover-se além da dicotomia livre-arbítrio versus determinismo e a reconhecer que possibilidades para agenciamento crítico e transformador não exigem que estabeleçamos um terreno incontestável e absoluto de conhecimento e experiência além das relações de poder.

34 Ibid., p. 148 . 
Que concepção pós-moderna de agenciamento é esta que Butler descobre no interior desta visão do sujeito como prática regulatória de significação? Aquela da repetição paródica ou repetição com uma diferença. Segundo afirma:

Se as regras que governam a significação não apenas restringem, mas possibilitam a afirmação de domínios alternativos de inteligibilidade cultural, ou seja, [no caso de gênero] novas possibilidades para gênero que conteste os rígidos códigos de binarismos hierárquicos, entāo, é apenas dentro das práticas de significações repetitivas que uma subversão da identidade torna-se possível. A injunção de ser um gênero determinado produz fracassos necessários, uma variedade de configurações incoerentes que, na sua multiplicidade, excedem e desafiam a injunção onde são geradas. ${ }^{35}$

Exemplos de significação repetitiva que desafiam e excedem injunções culturais poderiam incluir as práticas associadas com tais tipos limiares, tais como a "mulher masculinizada", o "homem efeminado", a "lésbica do batom", e o "gay macho". Todas essas figuras - realidades vividas, "experiências subservientes" - que ficam fora das normas hegemônicas de gênero desafiam sua coerência e estabilidade e prefiguram outras identidades - talvez, outros gêneros.

Com efeito, Butler recomenda genealogias no estilo foucaultiano das relações de dominação envolvidas nos mecanismos de produção identitária como uma forma de trazer essas identidades limiares ao foco. Ela tenta politizar os processos e categorias através das quais a identidade se forma. Uma política feminista da identidade que apela para um sujeito fundante "presume, fixa, restringe os próprios 'sujeitos' que espera representar e libertar". ${ }^{36}$ Assim, versões essencialistas da política da identidade restringem as possibilidades de configurações políticas alternativas. "Se as identidades não fossem mais fixas como premissas de um silogismo político, e políticas não fossem mais compreendidas como um conjunto de práticas derivadas dos supostos interesses pertencentes a um conjunto de indivíduos prontos, uma nova configuração de políticas certamente emergiria das ruínas das velhas., ${ }^{, 37}$

\footnotetext{
35 Ibid., p. 145

36 Ibid., p. 148.

37 Ibid., p. 149
} 
O que penso ser particularmente expressivo na posição de Butler é a sua articulação do argumento pós-estruturalista contra o sujeito humanista. É o sujeito fundacionista que é contestado, não as práticas de assumir posições de sujeito e representar-se. Com efeito, essas últimas são inevitáveis. Nem há uma negação do agenciamento; ele é simplesmente reformulado como regras variáveis dentro de processos regulatórios e costumeiros de significação. Pósestruturalistas como Foucault não negam que podemos ou devemos "constituir-nos como sujeitos", conforme atesta Hartsock, pois isso é inevitável. O que se contesta é o movimento epistemológico de basear nossas políticas num sujeito fundacional. Foucault e Butler querem mudar o foco da análise política do projeto epistemológico de amarrar teorias políticas e sociais para a análise da produção de certas formas de subjetividade em termos de seus custos. Os dois concluem que os custos associados às práticas modernas de formação identitária são muito altos. Finalmente, ambos parecem sugerir que desenvolvamos a compreensão de uma política que não seja amarrada a projetos epistemológicos fundacionais modernistas.

Wendy Brown, outra teórica feminista que aceita o desafio de Foucault para pensar além dos projetos emancipatórios feministas, é também muito atenta às avaliações feministas do custo de abandonar posses projetos fundantes. Em uma análise provocativa das motivações por trás das rejeições feministas do pós-estruturalismo, ela sugere que com uma visão muis-modernismo revelam uma afinidade modernista com uma visão muito anti-política:

[que] trai uma preferência por termos e práticas extrapolíticas: pela verdade ... em detrimeno de políticas...; por certeza e segurança ... em detrimento da liberdade...; por descobertas (científicas) em detrimento de decisōes (julgamentos); por sujeitos visíveis armados de direitos estabelecidos ao invés de pluralidades de difícil manejo e mutáveis arbitrando por si mesmas e por seu futuro, baseadas em nada além de que seus próprios hábitos e
argumento.

Brown desafia as feministas a desenvolverem uma política sem apelos fundacionistas à verdade e à autenticidade. Seu diagnóstico da condição feminista anti-pós-moderna é notável por

38 Brown, "Feminist Hesitations", p. 69. 
duas razões. Por um lado, diferentemente de Foulcault ou Butler, ela propõe uma visão coletiva e mais robusta da luta política - uma visão que chegue além das estratégias meramente reativas de resistência e subversão. Por outro lado, ela enfatiza a incoerência da relutância das feministas em derrubar o agente autônomo, auto-determinante, racional e predisposto da modernidade, que elas continuamente desafiaram por suas tendências masculinistas.

Qual o seu diagnóstico? Brown argumenta que a ligação feminista ao sujeito se enraíza numa relutância em desistir do projeto de amarrar a autoridade moral e epistemológica das "experiências, sentimentos e vozes das mulheres como fontes e certificados de verdade política pós-fundacional".39 Enquanto a maioria das teóricas feministas abraça alguma versão da construção social de gênero, muitas relutam a abandonar sua compreensão do despertar da consciência feminista como revelador de verdades escondidas das experiências das mulheres. Assim, elas participam daquilo que Foucault descreveu como "o estratagema da confissão", ou seja, a idéia de que a "confissão libera, mas o poder reduz ao silêncio." tentar defender um território de verdade que esteja além do domínio da construção social e por isso seja incontestável, as teorias feministas se envolvem em incoerências paradoxais. Por um lado, reconhecem que identidades femininas são construídas sob condições patriarcais e, por outro, tentam assegurar um território de verdade que esteja além dessa cena de construção. Mais uma vez, Brown comenta: "No interior de uma estrutura confessional, mesmo quando a construção social é adotada como método para explicar o fazer do gênero, 'sentimentos' e 'experiências' adquirem um status que é politicamente, se não ontologicamente, essencialista - além da hermenêutica." Al Além disso, pergunta: "O que há com o feminismo que tem medo da substituição de verdade por política, filosofia por luta, conhecimento privilegiado por uma cacofonia de vozes desiguais vociferando por posicionalidade?" 42

Brown recorre a Nietzsche para desenvolver seu diagnóstico e, tomando sua análise da moralidade como uma invenção dos sem poder

\footnotetext{
39 Ibid., p.71.

40 Michel Foucault, citado in Brown, "Feminist Hesitations", p.73.

4 Brown, "Feminist Hesitations", p.73.

12 Ibid.
} 
para reivindicar sua parcela na vida, conclui que "muito do feminismo do Atlântico Norte compartilha profundamente tanto do espírito epistemológico quanto da estrutura política do ressentimento." ${ }^{,+3} \mathrm{Ou}$ seja, Brown afirma que as feministas não querem desistir do privilégio epistêmico das suas reivindicações morais contra a dominação. Não confiando na sua habilidade de ser bem sucedida e sem a força desses clamores absolutistas, elas continuam a buscar "explicações para o conhecimento que sejam inocentes de poder, que nos posicione fora do poder, [que] faça o poder responder à razão/moralidade e proíba reivindicações de explicabilidade em outra direção." ${ }^{44}$ Em resposta aos esforços feministas de preservar o mito moderno de uma verdade livre do poder, Brown pergunta: "O que nos seria exigido para vivermos e trabalharmos politicamente sem tais mitos, sem afirmarmos que o nosso conhecimento é incorruptível devido a uma força de vontade; sem insistirmos que nossas verdades são menos parciais e mais morais do que as 'deles'? Poderíamos aprender a contestar a dominação pela força e com uma visão alternativa da vida coletiva, mais do que através de desaprovação moral?"45

Assim, Brown adota a visão nietzschiana de Foucault da contestação ilimitada de interpretações concernentes à identidade e à forma de viver. Apesar disso, considera a posição nietzscheana excessivamente individualista. Em contraste, propõe o desenvolvimento de "espaços políticos pós-morais e anti-relativistas, práticas de deliberação e modos de arbitragem". ${ }^{46}$ A política de resistência foucaultiana é insuficiente também. Como Joan Cocks, Brown percebe a fraqueza de Foucault diante da questão da ordem e da autoridade como um esforço de refrear exigências de explicabilidade e justificativa. A política de resistência é mais uma reação ao poder do que um esforço para controlá-lo. Feministas pós-modernas devem suplementar a política de resistência com esforços deliberados para criar espaços democráticos nos quais se possa inventar e contestar visões e normas políticas. Além disso, devem substituir a política da identidade e suas postulações de experiência e interesse particulares incontestáveis por uma política da diversidade que parta de uma visão do bem comum. Brown conclui: "Estou sugerindo que apenas uma discussão política

\footnotetext{
Ibid., p.75.

Ibid., p. 76.

Ibid., p.77.

Ibid.
} 
orientada para a diversidade e o bem comum, para o mundo e não para o sujeito, que envolva a conversão do conhecimento específico de mundo de uma pessoa de uma posição situada (do sujeito) para uma expressão pública, oferece-nos a possibilidade de contrapor fragmentações sociais pós-modernas e desintegrações políticas. ${ }^{, 47} \mathrm{~A}$ política feminista da identidade cuja ênfase num sujeito emancipatório e seus interesses "privados" obscureceu outros projetos cruciais feministas, como o desenvolvimento práticas de argumento público e a criação de espaços públicos para discussões entre comunidades complexas e diversas.

Tanto a crítica pós-estruturalista de Butler quanto a de Brown acerca do sujeito do feminismo muda nosso enfoque para as características dominantes (os "custos") dos projetos epistemológicos feministas modernos tais como o de Hartsock. Butler minimiza a participação feminista em práticas exclusionárias e normativas de identificação de gênero e tenta salvaguardar políticas feministas ao apelar para estratégias de subversões das identidades. Ela questiona se os custos políticos associados à retenção de políticas de identidade de base gendrada poderiam pesar mais do que seus benefícios. Brown vai além de Butler e de Foucault ao explicitamente articular as demandas pela criação de novos espaços públicos para uma prática política feminista coletivista e democrática.

O que distingue esses projetos feministas pós-humanistas é o seu esforço imaginativo e ferino de confrontar a crítica foucaultiana do humanismo moderno. Seus argumentos convincentes sobre a posição paradoxal em que o feminismo é encontrado ao usar as ferramentas do próprio dono para desmantelar a casa. E concluem que uma dessas ferramentas, o projeto de desenvolver epistemologias fundacionistas com base num sujeito essencialista feminista, é completamente contraproducente. O que não fica claro no desfecho dessas críticas é o status da política de base identitária e as práticas a ela associadas.

Esses esforços para desenvolver uma política pós-humanista exigem que eliminemos apelos a gênero como base para lutarmos contra a opressão? Existem identidades disponíveis como base de organização política, para a construção de movimentos políticos unificados? Quais unidades, se houver, são desejáveis? Butler e

47 Ibid., p.81. 
Brown desafiaram os esforços feministas para construir uma teoria totalmente emancipatória acerca das fundações das experiências e interesses, mas nenhuma argumentou que gênero não é uma categoria de opressão, nem que política feminista é impossível sem um sujeito unificado e preparado. Ao contrário, Butler simplesmente alerta sobre as características opressivas das normas correntes de gênero definidas como foram sob condições de opressão. Ela rejeita apelos a um gênero reificado ou naturalizado. Ela também desafia a idéia de que "unidade" seja um pré-requisito para ação política. E pergunta: "Que tipo de política exige aquele tipo de compra adiantada de unidade? Será que uma coalizão não precisa reconhecer suas contradições e agir com essas contradições intactas?"48 Butler mostra-se claramente sensível a tendências à exclusividade, estreiteza, fechamento, autopreocupação e arrogância sempre encontradas nos grupos políticos de base identitária. E argumenta a favor de uma abordagem antifundacionista para políticas de coalizão.

Como vimos, Brown também desafia apelos a noções de identidades fixas, ou a um território autêntico, incontestável e inocente do feminismo. Presumivelmente, ela também admite o valor de bases políticas auto-conscientes de identificação, incluindo nossas identificações com outras mulheres, na medida em que elas tentam evitar o sentido destrutivo de comunidades existentes nas culturas políticas feministas contemporâneas.

Em lugar da política da identidade com base em alguma identificação naturalizada e essencializada, Donna Harraway, outra feminista influenciada pelo pós-estruturalismo, introduziu a noção de uma política baseada nas "afinidades" ou afinidades políticas. ${ }^{49}$ Ela recomenda que partamos dos escritos das mulheres de cor, mulheres cujo acesso não problemático às identidades tais como "afroamericanas", "asiáticas" e "mulher" foi negado devido às suas conotações sexistas e racistas, para aprender como construir unidades políticas "sem confiar na lógica da apropriação, incorporação, e classificação taxonômica." ${ }^{, 50} \mathrm{O}$ que distingue esses modos de

48 Butler, Gender Trouble, p.14.

49 Donna Haraway, "A Cyborgue Manifesto: Science, Technology, and Socialist Feminism in the Late Twenticth Century," in Simians, Cyborgues, and Women: The Reinvention of Nature (New York: Routledge Press, 1991). p.156.

50) Ihid., p. 157. 
formação de identidade é o seu caráter político auto-consciente. O que tentam evitar é a redução de políticas para projetos de autodescobrimento e transformação pessoal, ou para a formação de comunidades rigidamente definidas como contra-culturais. ${ }^{51}$

Essa nova identidade política oferecida por Harraway cristaliza-se na imagem do "ciborgue", uma identidade criada pelas próprias forças às quais nos opomos nas sociedades patriarcais capitalistas pós-industriais. Nem totalmente humana, máquina, ou anima, essa identidade desafia categorização e se compraz na fusão das fronteiras (humana-animal, humana-máquina, natureza-cultura), mas também assume responsabilidade pela sua construção. É uma entidade destituída de origens inocentes, mas que se opõe à dominação. Harraway descreve sua perspectiva como sendo de esperançosa possibilidade:

Da perspectiva dos ciborgues, liberados da necessidade de amarrar a política em "nossa" posição privilegiada de opressão que incorpora todas as outras dominações, a inocência do meramente violado, o território daqueles próximos à natureza, podemos ser possibilidade poderosas. Feminismos e marxismos caminharam sem chão nos imperativos epistemológicos do ocidente para construir um sujeito revolucionário a partir da perspectiva de uma hierarquia de opressões e/ou uma posição latente de superioridade moral, inocência e de grande proximidade com a natureza. Sem nenhum sonho original disponível de uma linguagem comum ou simbiose original prometendo proteção ..., o reconhecimento de "si mesma" como totalmente envolvida no mundo, libertanos da necessidade de enraizar políticas em identificações, partidos de vanguarda, pureza, e maternagem. ${ }^{52}$

A política do ciborgue de Harraway é especialmente interessante porque armazena e subversivamente repete elementos da política da identidade humanista. Contudo, é uma política da identidade que tem uma diferença. Por exemplo, ela envolve a continuação da prática de advogar pela escrita de narrativas de integrantes de grupos

\footnotetext{
51 Ver Diana Fuss, Essentially Speaking: Feminism. Nature, and Difference (New York: Routledge Press, 1989), p. 101.

52 Haraway, "A Cyborg Manifesto", p. 176.
} 
oprimidos. Parcialmente enraizada como é nas experiências de mulheres de cor, a visão de Harraway enfatiza a importância de contar histórias para políticas liberadoras, de fato, para a sobrevivência de grupos oprimidos. O poder para significar, para entrar na luta pelos sentidos é crucial em qualquer política feminista. Mas essas histórias não participam dos mitos de origem de feminismos e humanismos essencialistas; ao invés disso, exploram o tema da identidade nas margens de grupos hegemônicos e, portanto, desconstroem a autoridade e a legitimidade de narrativas humanistas dominantes ao expor sua parcialidade. Logo, as narrativas de grupos oprimidos são importantes na medida em que empoderam esses grupos ao dar-lhes voz na luta sobre interpretações sem reivindicar ser epistemicamente privilegiadas ou incontestáveis. A eles não é negada a "autoridade" da experiência, se por "autoridade" queremos dizer o poder de apresentar aqueli experiência como base para análise e, desta forma, criar novas autocompreensões. O que é negado é a autoridade inquestionada da experiência não analisada. Em lugar de "construir defesas de ... experiência," para usar a frase de Edward Said, elas promovem o seu conhecimento ${ }^{53}$, que aqui deve ser compreendido como totalmente envolvido nas relações de poder e não como um domínio de investigação autônomo e neutro do ponto de vista do poder.

E, quanto ao despertar da consciência, acredito que também possa ser salvaguardado dos resquícios da política emancipatória humanista. Conforme já argumentei antes, uma explicação pósestruturalista da subjetividade é compatível com os insights que amarram a prática feminista do despertar da consciência. Em alguns modelos, o objetivo desse despertar é simplesmente desenvolver consciência crítica e o reconhecimento da opressão e não descobrir uma experiência autêntica e compartilhada. Mais frequientemente, esse despertar leva à desestabilização do senso de identidade e não a um sentido de sujeito unificado. Com efeito, essa noção de despertar da consciência não é diferente da genealogia de Foucault. Ambas foram projetadas para desafiar auto-compreensões correntes e para criar o espaço de novas formas de subjetividade.

Contar nossas histórias para nós mesmas tem sido um instrumento importante para curar e construir movimentos feministas de base. Enfocar de modo muito estreito o abraço nietzschiano do

53 Ver Diana Fuss, p.115, para a citação de Said. 
fluxo e do caos dentro do sujeito é ignorar inclusive a sensibilidade nietzscheana para a necessidade de uma ilusão ou "ficção" de unidade para rejeitar a perda completa da identidade. Embora a política pessimista foucaultiana da finitude e incerteza nos negue conforto metafísico, não há razão porque nos seja negado o sentido de estabilidade e integridade provisória que advém do ordenamento do caos. De uma perspectiva feminista, a óbvia ausência de atenção à lógica do desejo e sentimento nos textos de Foucault representa uma lacuna importante. Ele descartou preocupações com o psiquismo e com o "cerne do ser" como sendo irremediavelmente disciplinares. Com efeito, essa ausência contribui para o tom distante e ascético de seu desejo inicial por anonimidade e auto-apagamento. Em textos mais recentes sobre o sujeito, seu foco muda do auto-apagamento para a auto-superação. Mesmo assim, a ele faltam o pathos e a sensibilidade nietzscheanos para o papel da dor e da raiva em projetos de formação da identidade. Além disso, pode-se interpretar sua desatenção para com a estabilidade e continuidade do sujeito como uma expressão de um ressentiment contra o passado. Desconsiderando sua etiologia, a ênfase de Foucault no afastamento do ser deve ser posta com essa sensibilidade para que possa ser útil para o feminismo. Foucault ignora a importância da manutenção da generosidade a "eus anteriores" que, segundo Adrienne Rich, é necessário para projetos "saudáveis" de transformações pessoais. Retomando as epígrafes deste artigo, pode-se dizer Foucault "aguça" a memória necessária a uma vida politizada, mas fracassa no aguçar dos sentidos.

As feministas devem continuar a discutir os custos pessoais da dominação patriarcal, através da atenção ao desenvolvimento de práticas de empoderamento de auto-criação e, ao mesmo tempo, evitar a tendência de reduzir política a transformações pessoais. Em seus esforços para desafiar as características desabilitadoras da política da identidade, críticos pós-humanistas ignoram essa crucial função exercida pelas comunidades contra-culturais. Naturalmente, usar nossas vozes simplesmente e afirmarmo-nos diante da violência e trauma associados à opressão parece por vezes muito radical quando comparado aos nossos silêncios e submissões. Mas embora a autoafirmação e a auto-estima aí envolvidas sejam cruciais à constituição dos sujeitos capazes de entrar na arena política, elas não são a mesma coisa. Conforme disse Adrienne Rich: apenas "Romper os silêncios, contar nossas histórias, não é suficiente. Podemos valorizar o processo e 
a coragem exigida sem acreditar que isso seja um fim em si mesmo"., As implicações políticas dessas narrativas individuais serão uma função de terem sido analisadas coletivamente, bem como estrategicamente organizadas em lutas políticas feministas. O valor de se construir identidades, para o feminismo, dependerá de como isso é feito.

O desafio pós-humanista para os feminismos modernistas, que associei à influência de Foucault, começa das nossas experiências, dos limites de identificação e de movimentos políticos baseadas nessas identificações. Esforços para prognosticar estratégias políticas alternativas provocadas por essas experiências ainda estão nos seus estágios iniciais, mas muitos dos problemas estão claros. Neste ponto, já mostrei que as feministas que desenvolvem alguns dos insights radicais de pós-estruturalismo foucaultiano não são obviamente deixadas sem ferramentas úteis para dar suporte a projetos feministas de transformação social. As maiores fraquezas nas análises feitas por Foucault, reveladas por aquelas feministas que têm maior simpatia ao seu projeto, incluem (a) o fracasso em discutir a especificidade de gênero de muitas das tecnologias políticas do corpo por ele descritas, e (b) a ênfase de Foucault na estratégia reativa de resistência sobre o projeto mais construtivo de prognosticar ordens alternativas. Uma interpretação benevolente desses fracassos seria ligá-los às preocupações autoconscientes de Foucault com a identidade e com o papel do intelectual.

Como foi visto, Foucault previu sua tarefa como sendo a de fornecer ferramentas para os outros usarem em contextos e lutas nas quais se encontrassem. A crítica foucaultiana das características totalizantes das teorias sociais emancipatórias e sua ênfase numa micropolítica local de resistência deixa-nos sem as fontes para identificar quaisquer estruturas globais de dominação? Precisamos de uma teoria da resistência para saber quais coalizões são mais passíveis de produzir resultados políticos desejados? Procurarei concluir respondendo a essas questões remanescentes relativas à identidade.

As respostas de Foucault para essas questões consistentemente nos remetem a contextos históricos e práticos de onde qualquer julgamento teórico e político emergirá. Ele não recusa a necessidade de justificativas e normas em teoria e luta política. Ele simplesmente enfatiza que as justificativas e normas às quais apelamos sempre

54 Rich, "Resisting Amnesia," in Blood, Bread and Poetry, p. 144. 
estarão sempre incluídas nas práticas que estamos criticando. Nossos julgamentos inevitavelmente envolverão análise comparativa histórica e social. Assim, não haverá universais trans-históricos para amarrar nossas críticas, nem teoria incontestável de dominação global para guiar uma praxis revolucionária unificada, para trazer a história para dentro do nosso controle. Além disso, ele enfatiza as características perigosas dos esforços para preparar tais teorias. Em nossas lutas políticas contra injustiça e opressão, as feministas podem continuar a apelar para os padrões de racionalidade e justiça que estão disponíveis nos contextos nos quais nos encontramos. Esses padrões não determinam univocamente uma decisão em detrimento de outra como elas são interpretadas é questão de luta política - mas não constituem terreno para a crítica.

Observador como era da tendência das abordagens teóricas dominantes de deixarem escapar certos domínios de experiência e prática - conhecimentos assujeitados, Foucault preferia escrever histórias cautelosas ao invés de endossar "ismos" particulares. Na condição de feministas, também temos boa razão de sermos cautelosas com os perigos do imperialismo teórico. As mulheres engajadas em lutas no terceiro mundo constantemente lembram as feministas ocidentais a respeito dos limites de nossas compreensões de justiça, direitos e liberação dos seus próprios movimentos. A relutância de Foucault em oferecer previsões globais, em tentar representar interesses universais é menos uma injunção para evitar pensar acerca de estruturas globais de dominação do que um esforço para permanecer sensível à necessidade de permitir às comunidades locais a liberdade de desenvolver suas próprias estratégias, prioridades, visões e compreensões da opressão. Mais do começar com pronunciamentos e presunções de universalidade, ele recomenda que os intelectuais tentem fornecer ferramentas para a crítica local dentro de setores específicos onde suas vidas e trabalhos os situem. É assim que ele descreve os objetivos de seus próprios projetos históricos. Michael Kelly apropriadamente caracteriza a posição de Foucault ao dizer:

Quanto às normas mais específicas que governam a resistência - quem deve resistir a que, quando e como, e se algumas formas de resistência são mais desejáveis do que outras -, Foucault argumenta que crítica "deve ser um instrumento para aqueles que lutam." Ou seja. ele 
endereça essas questões normativas sobre renitência enquanto assuntos práticos e não teóricos... [conforme] justificado no contexto de uma prática. ${ }^{55}$

Realmente, a retórica de Foucault é quase sempre masculina, sua perspectiva androcêntrica, sua visão pessimista. Contudo, o que espero ter mostrado é que seus métodos e histórias cautelosos têm sido úteis e produtivos para intelectuais feministas que lutam para combater tendências perigosas e despolitizantes dentro da teoria e da prática feminista - intelectuais feministas que não compartilham nem de seu androcentrismo nem de sua relutância em oferecer visões diretivas. Apesar disso, ele levanta a questão da existência de formas alternativas de compreender a identidade do intelectual e as funções da teoria. Além disso, ele nos obriga a reconsiderar o valor das teorias e práticas emancipatórias que nos foram legadas dentro das tradições capitalistas ocidentais. Nesse particular, sua obra tem alimentado impulsos autocríticos dentro do feminismo que são indispensáveis.

55 Michael Kelly, "A critique of Habermas' Interpretation of Foucault," manuscrito inédito. 